\title{
The Role of Emotional Intelligence in Enhancing Organizational Effectiveness: The Case of Information Technology Managers in Jordan
}

\author{
Ra'ed Masa'deh \\ School of Business, The University of Jordan, Amman, Jordan \\ Email: r.masadeh@ju.edu.jo
}

Received 15 April 2016; accepted 21 June 2016; published 24 June 2016

Copyright (C) 2016 by author and Scientific Research Publishing Inc. This work is licensed under the Creative Commons Attribution International License (CC BY). http://creativecommons.org/licenses/by/4.0/

(c) (i) Open Access

\begin{abstract}
The aim of this research is to explore the role of emotional intelligence (awareness of one's own emotion, management of one's own emotion, awareness of other's emotion, and management of other's emotion) on organizational effectiveness in Jordanian public shareholding firms. A total of 154 questionnaire containing 29 items was used to collect information from the respondents. Multiple regression analysis was conducted to test the research hypotheses. Results of the current study revealed that there were significant positive impacts of management of one's own emotion, awareness of other's emotion, and management of other's emotion on organizational effectiveness, whereas awareness of one's own emotion did not have a significant impact on organizational effectiveness. Also, the results revealed that there was no significant difference in the impact of emotional intelligence on organizational effectiveness that could be attributed to gender. On the other hand, results of ANOVA test indicated that there were significant differences in the impact of emotional intelligence on organizational effectiveness in favor of age and experience.
\end{abstract}

\section{Keywords}

Emotional Intelligence, Organizational Effectiveness, Jordan

\section{Introduction}

According to [1], over the past decade, Jordanian researchers have shown increasing interest in studying Emotional Intelligence (EI). At the time of writing this research a keyword search for EI in the Jordan University 
e-Library Database returned 11 studies, conducted between 2005 and 2013, on the relationship between EI and a number of outcomes. The most relevant to the present research studies of the impact of EI training on Job Satisfaction (JS) among nurses [2] and the influence of EI on effectiveness of project managers [3]. The findings of the research by [3] conducted among 59 project managers from the companies registered in Amman Chamber of Commerce revealed a positive relationship between EI and effectiveness. [2], who studied the relationship between EI and JS among nurses in King Abdulla II hospital in Jordan found significant positive correlation between EI and JS. She suggested investigating further the relationship among EI, Job Performance (JP), and Organizational Effectiveness (OE) in different settings and organizations in Jordan.

Moreover, it is known that EI as a construct originated from Western psychology, and it is yet to demonstrate how relevant it is in other cultures. Even though basic emotions are considered universal, adaptive emotional behaviors may vary from culture to culture and there may be variations in some aspects of emotional functioning in different cultures [4]. Thus, conducting the study in a Non-Western culture is a valuable contribution to the body of knowledge about EI. This study, as far as we know, is among the fewest studies that explore the role of emotional intelligence in terms of awareness of one's own emotion, management of one's own emotion, awareness of other's emotion, and management of other's emotion on organizational effectiveness in Jordanian public shareholding firms from the Information Technology (IT) managers' perspectives. In addition to this introduction, this study includes five more sections. Section 2 presents a brief revision for the relevant literature. Section 3 exposes the study methodology. Then, Section 4 describes data analysis and results. Finally, Section 5 presents the discussions and concludes.

\section{Literature Review}

Several different models of EI have evolved offering different conceptualizations and definitions. This lack of agreement regarding the definition of EI has resulted in the development of different measures to assess it. According to [5] what different EI conceptualizations share is that they all describe one or more aspects of personality. At the same time, [6] suggest that the different EI models all revolve around the premise that it is an emotional ability, that similar to cognitive ability and competency, must be considered in the prediction of successful adaptation. Therefore, the controversy that surrounds the definition of EI maintains a debate among researchers on how EI can be measured, and whether EI is an ability, personality trait, or a mixed set of skills and competencies [7].

Three main models of EI are used widely in the literature: Mixed Models (introduced by [8] in 1995), the Trait Model (introduced by [9]), and the Ability Model (introduced by [10]). In general, all three models are concerned with understanding and measuring the components involved in the awareness and management of one's emotions and the emotions of others ([8]; cited in [11]). Other researchers see that with respect to the elements they encompass, the different models of EI may be complementary rather than contradictory [12]. The following passages will present these three main models of EI.

The two mixed models presented are popular models that define EI as a constellation of personality attributes [5]. They are Goleman's Mixed Model of EI and Bar-On’s Mixed Model of EI. Daniel Golemancame across the study of Mayer and Salovey and subsequently made EI popular though his book "EI: Why it can matter more than IQ”. Goleman's EI construct originally contained four main pillars: self-awareness, self-management, social awareness, relationship management. Unlike other measures, each of the pillars or constructs included a list of emotional competencies, which are learned in relation to the general EI he believed people are born with. Goleman considers EI as a significant predictor of success in the workplace and later elaborated on EI as a combination of five components in total: self-awareness, emotional self-regulation, empathy, motivation and social skills [5]. Bar-On defined EI as a set of broad factors: intrapersonal, interpersonal, adaptability, stress management, and general mood [11]. He theorized that they can be improved gradually through training, programming, and therapy ([13] cited in [11]) enabling a person to successfully cope with external demands and pressures. The wide-ranging nature of these factors has put Bar-On under criticism for combining too much under the same umbrella concept [11].

Trait EI model was presented as an alternative conceptualization of EI in order to address the challenges related with measuring abilities and competencies via self-reports as done by researchers using mixed models of EI. Trait EI (or emotional self-efficacy) is defined as a combination of emotion-related self-perceptions and dispositions located at the lower levels of personality hierarchies ([14] cited in [15]). The model sees EI as a trait 
that can be represented as fifteen underlying qualities (in adult samples): adaptability, assertiveness, emotional expression, emotional management (of others), emotional perception, emotional regulation, impulsiveness, relationships, self-esteem, self-motivation, social awareness, stress management, trait empathy, trait happiness, trait optimism. Trait EI is thus seen an overarching personality factor that represents the person's emotional self-confidence [15]. Like conventional personality traits, Trait EI represents a qualitative style of behavior and experience that is adaptive in some contexts but not in others; or in other words qualities or traits that relate directly to emotional functioning (e.g. assertiveness, empathy). A focal research challenge then, to researchers in this culture, is to integrate Trait EI and its facets into standard personality research.

Trait EI is the only operational definition in the field that recognizes the inherent subjectivity of emotional experience. That the Trait EI facets are personality traits, as opposed to competencies or mental abilities or facilitators, is also corroborated by research revealing that the same genes that are implicated in the development of individual differences in the Big Five personality traits are also implicated in the development of EI ([14] cited in [15]). Doctor John Mayer and Doctor Peter Salovey were the first who formalized the concept of EI in 1990 [10]. Later in 1997 they revised their theory of EI defining it as "the capacity to reason about emotions, and of emotions to enhance thinking. It includes the abilities to accurately perceive emotions, to access and generate emotions so as to assist thought, to understand emotions and emotional knowledge, and to reflectively regulate emotions so as to promote emotional and intellectual growth” ([15], p. 197). [16] understand EI as a connection of two components: "Emotions" and "Intelligence". "Emotions" refer to affect, feelings, moods while "Intelligence" to logic, reasoning, judgment and logical thinking. "EI" thus was seen as the way emotions affect person's reactions to situations. Therefore EI is a construct that combines emotions with cognition, enabling heightened emotional or mental abilities [17].

[17] definition of EI suggests that EI is divided into four branches. The four branches of ability EI are as follows: Perception, identification and expression of emotions. This indicates the ability to identify one's own emotions and other's emotions through recognizing their feelings, thoughts, studying their appearance and behavior. It also suggests the ability to express honest feelings and emotions. The use of emotions to facilitate thought. Meaning to be able to reason with emotions, and use emotions to generate intellectual thinking. For example, recognizing one's emotional state or mood can help solve a problem or even change the individual's perspective and judgment. Understanding and analyzing emotions. This branch involves identifying emotions and understanding the difference between the various stages that emotions have. It also means understanding that feelings can be complex and transitional, resulting to different layers of emotions, such as like, love, admiration, hate, anger, shame, sadness, etc. Managing and regulating emotions to promote personal growth. This means accepting negative feelings and learning how to deal with them; detaching from negative ones, and using positive feelings to enhance emotional and intellectual growth. Managing emotions can also mean to continuously monitor emotions and determine whether they are useful, informative, influential or unreasonable.

Ability model was chosen over Mixed EI and Trait EI model because it has several advantages. For one, [17] definition of EI is considered to be the most recognized one among scholars [18]; it has generated the largest number of researches published in peer review journals for its "solid and justified theoretical base and support by empirical data" obtained from basic and applied fields [18]; [16] suggest that it is an advantage that ability EI definition does not include achievement orientation or initiative that could be found in the mixed models, because those are considered conceptually distinct personality characteristics and they are not directly connected either to emotion or intelligence. Their approach to EI meets the standards of intelligence and it demonstrates solid convergent and discriminant validity to support its claims to be intelligence [16].

[19] conducted a research on a sample of 250 employees working in public sector banks, cooperative banks and insurance companies in Haranaya, India. It found a significant influence of EI on JP of employees $(\beta=0.63$, $\mathrm{t}=12.32, \mathrm{p}<0.001$ ) where the multiple regression model explained $39 \%$ of the change in JP. [20] in their article "EI and scholastic performance among children of a high school in South of India" conducted a research among 295 students in a school In Bangalore, India ages 12 - 16, from which 164 are boys and 131 are girls, with the aim of evaluating their EI and how it can affect their academic performance. EI is universally defined as a person's ability to recognize and monitor their own emotions and feelings as well as others', and to be able to use it to control their behaviors and way of thinking. [20] found that girls scored drastically higher than boys in all three domains of EI and that having high regulations on one's emotions is significantly associated with better and higher scholastic performance, while attention and clarity factors don't play a huge part. [21] studied the relationship between an employee's EI, and three work related factors: JS, JP, and commitment. The study 
was made for the employees of Fars province industries in Iran. JS is defined in the article, is simply put, how people react to their jobs and what they like and dislike about it, their responsibilities, environment. Commitment is defined as how much an employee is loyal to and believes in a company and its values. JP describes the degree an employee performs the job well and contributes in the outcomes and success of a company. The results showed that employees with high levels of EI are more satisfied with their jobs, can adapt with working situations, have a positive attitude towards problems and can easily tackle them, hence perform their job well. [22] conducted the study to explore how EI and adjustment differentially predict managerial JP when moderated by emotional labor. The sample consisted of 161 managers from 37 companies. Results showed the hypotheses were not supported, that is to say that emotional labor did not moderate the relationships between EI and adjustment with performance.

[23] wrote an article titled "The Relationship between EI and JS among Westcol FET lecturers". The results of the study conducted among sample size of 56 lecturers from Westcol demonstrated that there was a statistically significant relationship between EI and JS. [24] explored the effects of EI on JS as an empirical study on call center employees. The aim of this research was to empirically investigate, the impact of EI on JS. [25] considered EI as a multidimensional construct and compares the effects of these dimensions on JS and JP. Data obtained from 147 call center employees in Istanbul we used to examine the hypothesized relationships among study variables. The results of the study showed significant positive relationship between EI and internal satisfaction. The research by [26] titled "Relevance of EI for effective JP: An empirical study" was carried out in various private and public sector organizations in Delhi NCR and the sample consisted of 90 executives. The research findings demonstrated statistically significant positive correlations between EI and performance. In other words, it means that increased EI scores were linked with increased JP. [26] investigated the relationship between EI, JP and positive affect towards the workplace. They moved into a new direction of EI study to explore the relationship between different components of JP such as salary, percent merit increase and company rank, and EI. The sample for present research consisted of 44 analysts and clerical employees from the finance department of an insurance company. The research team used the Mayer-Salovey-Caruso EI measure for EI and gathered information about salaries to indicate JP. It was found that emotionally intelligent individuals received greater merit increases and held higher company ranks as well as greater peer and supervisor ratings of interpersonal facilitation and stress tolerance than their counterparts.

Nevertheless, the results of the study by [27] that was conducted among the management department of a health care organization, found no correlation between EI and JP. The fact that the findings about the relationship between EI and JP in the literature have been mixed ([8] [13] [28]) indicates potential for exploring the link between EI and JP further. Indeed, [29] examined how EI affects emotional exhaustion resulting from emotional labor, and how emotional exhaustion influences JP in terms of organizational commitment and JS. Sample size consisted on 295 retail sales employees in South Korea. It was found that 3 factors, namely appraisals of emotions, optimism, and social skills are negatively associated with emotional exhaustion but the fourth factor of utilization of emotion showed no significant links with emotional exhaustion. Emotional exhaustion was found to be negatively related to JP in terms of organizational commitment and JS and the mediating effect of emotional exhaustion was confirmed in the relationship between JP and appraisals of emotions, optimism, and social skills as factors in EI. [27] conducted a study called "The relationship of EI test scores to JP evaluation scores in the management group of a health care organization”. The sample in the study were 78 professionals from management group composed of the executive team, department directors, assistants, coordinators, professionals, technicians, clericals and others from a medium sized, regional medical center located in the Midwestern United States. The study did not find correlation between EI and JP.

[29] examined the resources on the factors that contribute or promote emotional and social intelligence competencies. The author suggests that one of the factors that influence a students' knowledge and skills is the instructor's Emotional and Social Intelligence Competence (ESIC) which could be understood as caring and nurturing attitude, forming emotional connection, concern for student's progress and ability to accurately communicate feelings and understand students' perspectives, contribute to defining social and emotional competence of the instructors. He points out that students feel connected with their instructors if they receive support and encouragement from them. [30] explored the influence of rewards and JS on employees in the service industry. Their study aimed to find out the relationship between employees' rewards, and the dimension of their JS. Samples consisted of 104 workers from two large Ghanian private organizations. The study found that JS increased with rewards and as it did so, so did employees' loyalty to the organization. The study underlines the role of 
employees' JS and the responsibilities of organizations in fostering good quality HRM practices in the service sectors in employee satisfaction and performance. These results add to the evidence that HR practices influences business outcomes.

[31] studied discussed the relationship between EI and Organization Citizenship Behavior (OCB). A research was conducted to study how an employee can use his emotions, understand them, as well as control them, in order to increase his loyalty and citizenship behavior towards his organization, hence positively enhance the effectiveness of an organization. In this article, the authors defined EI as an ability to perceive, use, understand and manage emotions. OCB is defined as the behavior of employees that affects the efficiency and development of an organization's functioning. The research was conducted on two samples of people, young working students, mostly males, and relatively older professors, mostly females. In the first one, using and managing emotions were the greatest contributors to OCB. Whereas in the second study, only managing emotions was the contributor. In general, the results showed a positive link between EI and OCB. [32] explored the relationship between General Intelligence (GI), EI and how they affect the stress levels and reactivity in a person. EI is defined in the article as an ability to recognize emotion, reason with emotion and emotion-related information, and process emotional information as part of general problem solving. Researchers conducted a study on 34 healthy 18 - 30 years old male students to examine their GI and EI levels, as well as their stress and stress reactivity levels, and to explore whether GI and EI affect stress levels, and which has the larger effect. The results showed that EI is linked inversely with stress levels. The higher the EI levels, the less stressed a person is; whereas GI has no significant relation to stress levels. As a conclusion, using emotions, understanding and controlling them, can attribute in decreasing severe stress levels in the human body.

[33] studied teacher effectiveness in relation to EI among medicine and engineering faculty members. These two have been seen as the most demanding fields of higher education, causing high levels of stress to students enrolled in their programs. Medicine and engineering teachers play an important role in decreasing the stress levels in their students, the more effective and successful their teaching is, the less stressed their students become. The research in this article studies whether EI affects the teacher's performance in the faculty of medicine and engineering. The authors studied EI as predictor of JP besides two elements that contribute to the success of a teacher: knowledge of the subject, and knowledge of the various teaching methods. Results showed that EI highly affects their performance. The authors explained a few components that underlie EI: emotional stability, self-awareness, self-motivation, managing relations, and integrity are a few of them. The higher the EI is, the better performance as a teacher. [34] studied the relationship between EI and transformational leadership of physical education managers of Golestan state in Iran. Forty-seven managers and deputies of physical education departments were selected as statistical samples of this research. The results of their study that was conducted using questionnaire indicated that there is a significant relationship between EI and transformational leadership $(r=0.61)$. [35] explored how EI and people's emotional behaviors can affect their managerial effectiveness; their skills as managers. Managerial effectiveness is defined in the article as the competency of managers, their leadership skills, how well and successfully they can perform their responsibilities in their position, and their ability to achieve the needed requirements in order to bring out what's best for the company development. The study focused on studying how EI and rational emotive behavior affect the effectiveness of managers. Studies were conducted on 305 managers from different private and public sectors. Researchers concluded that there was a big positive relationship between EI and managerial effectiveness, and that rational emotive behavior helped moderate the relationship between the two variables.

[6] explored the link between EI and Entrepreneurial Orientation (EO) within small firms, which was the primary purpose of their study. The secondary purpose of their research was to explore the nature of EI and EO relationship by exploring micro-connections between EO and EO dimensions. Their research sample consisted of 35 owner-managers of small young companies from high-tech industry in Sweden. They used EISDI tool to measure EI. Both hypotheses were rejected. It was found that an owner-manager's EI cannot be used to predict EO within small firms. [36] explored the associations among EI, emotional labor and work effectiveness in service organizations. The authors of the given research draw the parallels between studies on EI and emotional labor and analyze its effects on work effectiveness in different business contexts; professional service, service shop and mass service. The research sample consisted of 167 responses from service providers and their managers and showed that, counter-intuitively, the influence of self emotional appraisal on team role effectiveness is positive for those with low work motivation while for the high work motivation group; the effect is initially positive but turns negative at the high self emotional appraisal levels. The effect of others' emotional appraisal on 
team role effectiveness is higher for low work motivation group and for both low and high motivation groups; the moderation effect is positive at the low to moderate levels of others' emotional appraisal but becomes negative at high levels of others' emotional appraisal. Also the role of EI and emotional labor in affecting service quality is dependent on the type of service organizations. [37] explored developing and measuring the EI of leaders. Total sample consisted of 535 fully employed business students at a medium-sized public university in the Southwestern USA participated in this research. The results show that EI can be intentionally developed; the treatment group demonstrated statistically significant overall EI gains and across each EI dimension, whereas the control group did not demonstrate any significant pre-/post-test differences. [38] in their research called "EI competencies in the team and team leader" collected data from 422 respondents from 81 teams in a military organization. The results of their research showed that team leader EI was strongly related to the presence of emotionally competent group norms on the teams they lead, and that emotionally competent group norms were related to team performance. [39] in their article "Business-unit-level relationship between employee satisfaction, employee engagement, and business outcomes: a meta-analysis” presented a study that combined information from 7939 business units in 36 companies and used meta-analysis method to examine the relationship between employee satisfaction - engagement and business-unit outcomes (customer satisfaction, productivity, profit, employee turnover, and accidents). Generalizable relationships large enough to have substantial practical value were found between unit-level employee satisfaction-engagement and these business-unit outcomes.

To sum up, there is inadequate research on the relationship between emotional intelligence and organizational effectiveness. Consequently, conducting this study in the context of IT managers will contribute to developing better understanding of the implications of emotional intelligence in organizational settings. Furthermore, this study is interested in investigating a relationship that has not been extensively studied in previous work. Recent studies show growing interest in conducting studies on emotional intelligence, which has led to an improvement in the conception of emotional intelligence and its demonstrated ability to predict important work outcomes, and continue to reveal a wide range of potential applications of emotional intelligence. Nevertheless, the majority of these studies were focused on the applications of emotional intelligence within the business field, in addition to the findings being mixed. There are currently several different definitions and measuring instruments of emotional intelligence which indicates vast opportunity to continue developing a better understanding of emotional intelligence. Therefore, it is anticipated that conducting the study on emotional intelligence in a public sector organization in Jordan may add to the body of knowledge and develop deeper understanding of emotional intelligence and how it affects organizational effectiveness.

\section{Research Methodology}

This section provides the methodology applied in the current study. It consists of the research model, operational definitions of the study's independent and dependent variables, research hypotheses, besides data collection tool and research population and sample.

\subsection{Research Model}

The major elements of this research are established based on preceding literature, either theoretically or empirically. Indeed, this study used variables that are common in emotional intelligence literature. Figure 1 represents a model for the study that shows the independent variables within the construct of emotional intelligence, and the dependent variable (organizational effectiveness), and the proposed relationship between them.

\subsection{Operational Definitions}

The current research considers four independent variables within the construct of emotional intelligence, and one dependent variable (organizational effectiveness). Further, emotional intelligence includes awareness of one's own emotion, management of one's own emotion, awareness of other's emotion, and management of other's emotion. According to [40], awareness of one's own emotion, which was measured in the research questionnaire through 4 items, referred to the ability to discuss and disclose emotions, whereas management of one's own emotion, which was measured in the research questionnaire through 4 items is the ability to delay or withhold strong emotional reactions, awareness of other's emotion was measured in the research questionnaire through 4 items, referred to the ability to read faces and body language, and management of other's emotion, 


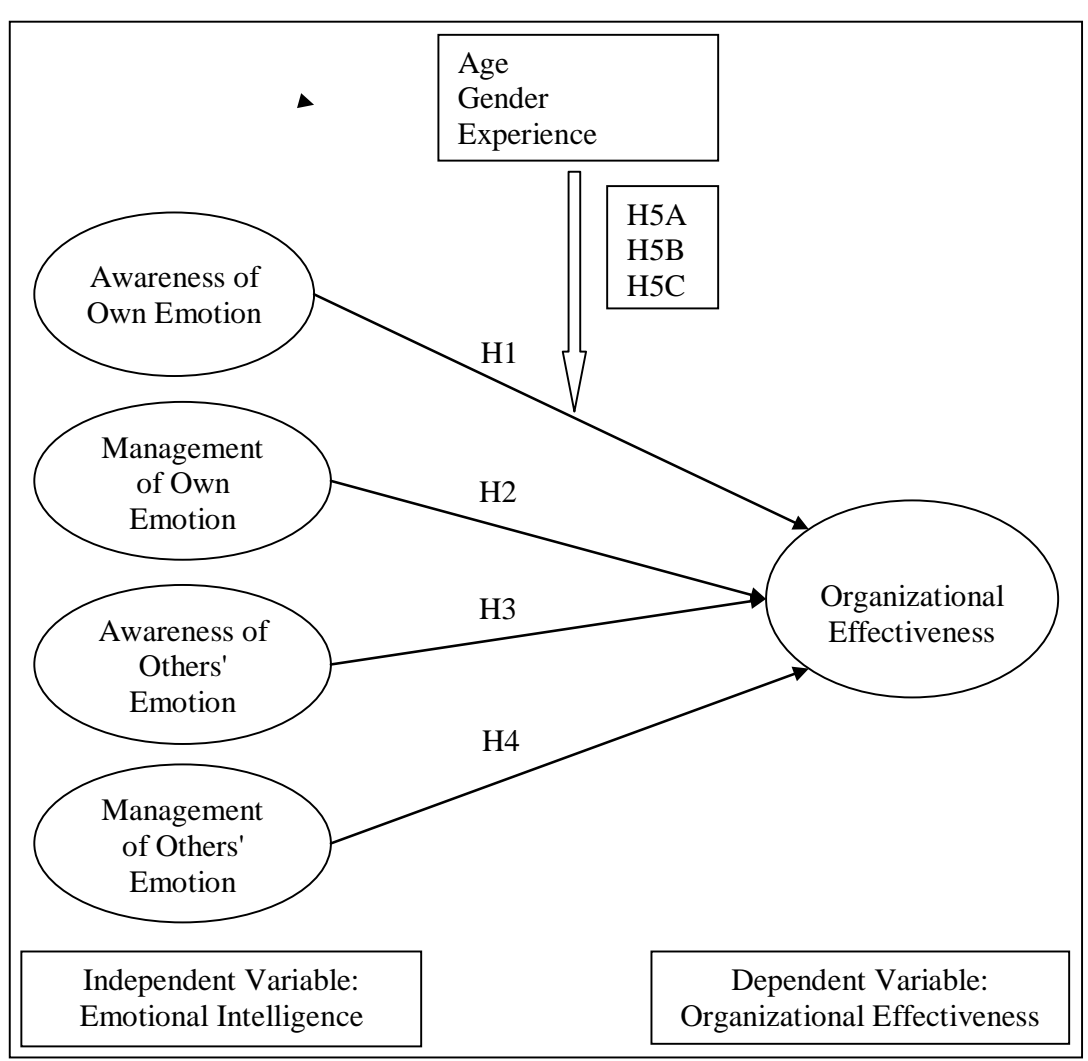

Figure 1. Research model.

which was measured in the research questionnaire through 4 items, defined as the ability to positively influence others' emotions. However, the four previous independent variables were validated by [41]. Organizational effectiveness was derived from the scale developed by [42] measured using 14 items, however, after piloting the survey items on five lecturers who are specialized in the business management discipline, one item was removed. Therefore, organizational effectiveness was measured by 13 items.

\subsection{Research Hypotheses}

In order to test the research model of the impact of emotional intelligence on organizational effectiveness, the study is hypothesized as follows:

H1: There is a statistically significant impact of awareness of one's own emotion on organizational effectiveness.

H2: There is a statistically significant impact of management of one's own emotion on organizational effectiveness.

H3: There is a statistically significant impact of awareness of other's emotion on organizational effectiveness.

H4: There is a statistically significant impact of management of other's emotion on organizational effectiveness.

H5A: There is a significant difference in the impact of emotional intelligence on organizational effectiveness due to gender.

H5B: There is a significant difference in the impact of emotional intelligence on organizational effectiveness due to age.

H5C: There is a significant difference in the impact of emotional intelligence on organizational effectiveness due to experience.

\subsection{Population and Sampling}

The targeted population of this study consisted of all IT managers who work in public shareholding firms in 
Jordan. Indeed, surveys were distributed to 190 Jordanian IT managers in which 154 were returned resulted in a high response rate of $81 \%$. Furthermore, according to Morgan Table data, 127 managers should be reached as the size of statistical sample of this research [43], consequently, data was adequate for statistical analysis. The questionnaire consisted of two sections; the first section in questionnaire presents general personal information about a respondent, the gender, age, and years of experience. The second section includes questions to measure the independent and dependent variables.

\section{Data Analysis and Results}

In order to explore the impact of emotional intelligence on organizational effectiveness, in which these variables have been measured using 5-points Likert scale that varies between not agree at all = 1 and totally agree $=5$; reliability and validity analyses were conducted, descriptive analysis was used to describe the characteristic of sample and the respondent to the questionnaires besides the independent and dependent variables. Also, multiple regression analysis was employed to test the research hypotheses.

\subsection{Validity and Reliability}

Validity and reliability are two important measures to determine the quality and usefulness of the primary data. Validity is about accuracy and whether the instrument measures what it is intended to measure while reliability is about precision; it is used to check the consistency and stability of the questionnaire. Indeed, the researchers depended on scales and items that were previously developed and used by other researchers with similar interest. Also a draft of the questionnaire was formulated, and then it was reviewed by five academic lecturers-who have a sufficient knowledge and experience in this scope to insure that each item is measuring what is intended to be measured, and to avoid the ambiguity and complexity in the phrasing of questions. The reliability of the instrument was measured by the Cronbach's alpha coefficient. Further, some scholars (e.g. [44]) suggested that the values of all indicators or dimensional scales should be above the recommended value of 0.60 . Table 1 represents the results of Cranach's alpha for the independent and dependent variables. Cronbach's alpha coefficients of all the tested variables are above 0.60 which suggesting the composite measure is reliable.

\subsection{Respondents Demographic Profile}

As indicated in Table 2, the demographic profile of the respondents for this study showed that they are typically males, most of them 30 years old and more, and most of the respondents have five years and above.

\subsection{Descriptive Analysis}

In order to describe the responses and thus the attitude of the respondents toward each question they were asked in the survey, the mean and the standard deviation were estimated. While the mean shows the central tendency of the data, the standard deviation measures the dispersion which offers an index of the spread or variability in the data [43]. In other words, a small standard deviation for a set of values reveals that these values are clustered closely about the mean or located close to it; a large standard deviation indicates the opposite. The level of each item was determined by the following formula: (highest point in Likert scale-lowest point in Likert scale)/the number of the levels used $=(5-1) / 5=0.80$, where $1-1.80$ reflected by "very low", $1.81-2.60$ reflected by "low”, 2.61 - 3.40 reflected by “medium”, 3.41 - 4.20 reflected by "high”, and 4.21 - 5 reflected by "very high”.

Table 1. The Cronbach's alpha coefficients of study variables.

\begin{tabular}{ccc} 
Variables & Number of items & Cronbach alpha \\
Awareness of Own Emotions & 4 & 0.846 \\
Management of Own Emotions & 4 & 0.778 \\
Awareness of Others' Emotions & 4 & 0.859 \\
Management of Others' Emotions & 4 & 0.843 \\
Organizational Effectiveness & 13 & 0.898 \\
\hline
\end{tabular}


Then the items were being ordered based on their means. Table 3 and Table 4 show the results.

As presented in Table 3, data analysis results have shown that emotional intelligence is applied to a moderate extent in the Jordanian public shareholding firms in which the mean score is 3.185. This is an indicator on the reflectance of emotional intelligence, and such medium level of presentation denotes a modest attitude regarding the concept of emotional intelligence. In addition, organizational effectiveness found to be moderate as well. This advocates that public shareholding firms is currently not paying a great attention to the IT managers' effectiveness. Table 4 demonstrates the mean, Standard Deviation (SD), level, and order scores for emotional intelligence and organizational effectiveness items.

\subsection{Hypotheses Testing Results}

The current research is mainly seeking to investigate the impact of emotional intelligence (awareness of one's own emotion, management of one's own emotion, awareness of other's emotion, and management of other's emotion) on organizational effectiveness in Jordanian public shareholding firms. Consequently, in order to test the hypotheses developed for this study, multiple regression technique was used. Further, the level of significance ( $\alpha$-level) was chosen to be 0.05 and the probability value (p-value) obtained from the statistical hypotheses test is considered to be the decision rule for rejecting the null hypotheses [45]. If the p-value is less than or equal to $\alpha$-level, the null hypothesis will be rejected and the alternative hypothesis will be supported. However, if the p-value is greater than the $\alpha$-level, the null hypothesis cannot be rejected and the alternative hypothesis will not be supported. In addition, normality of the independent variables and the absence of multi co-linearity problem (a case of multiple regression in which the independent variables are themselves highly correlated) were

\section{Table 2. Description of the respondents’ demographic profiles.}

\begin{tabular}{cccc}
\hline Category & Category & Frequency & Percentage\% \\
\hline \multirow{2}{*}{ Gender } & Males & 114 & 74.0 \\
& Females & 40 & 26.0 \\
& Total & 154 & 100 \\
Age & 24 years-less than 30 & 14 & 9.3 \\
& 30 years-less than 40 & 84 & 22.0 \\
& 40 years-less than 50 & 34 & 14.2 \\
& More than 50 years old & 22 & 100 \\
Experience & Total & 154 & 18.8 \\
& Less than 5 years & 29 & 60.4 \\
\hline
\end{tabular}

Table 3. Overall mean and standard deviation of the study’s variables.

\begin{tabular}{|c|c|c|c|c|c|}
\hline Type of Variable & Variables & Mean & Standard Deviation & Level & Order \\
\hline \multirow[t]{5}{*}{ Independent Variables } & Emotional Intelligence & 3.185 & 0.761 & Medium & \\
\hline & Awareness of Own Emotions & 3.167 & 0.930 & Medium & 2 \\
\hline & Management of Own Emotions & 3.045 & 0.848 & Medium & 4 \\
\hline & Awareness of Others' Emotions & 3.407 & 0.881 & High & 1 \\
\hline & Management of Others’ Emotions & 3.123 & 0.877 & Medium & 3 \\
\hline Dependent Variables & Organizational Effectiveness & 3.054 & 0.742 & Medium & \\
\hline
\end{tabular}


Table 4. Mean and standard deviation of the study’s variables.

\begin{tabular}{|c|c|c|c|c|}
\hline Awareness of Own Emotions & Mean & SD & Level & Order \\
\hline I can explain the emotions I feel to my colleagues. & 3.08 & 1.16 & Medium & 4 \\
\hline I can discuss the emotions I feel with other colleagues. & 3.09 & 1.08 & Medium & 3 \\
\hline If I feel down, I can tell my colleagues what will make me feel better. & 3.12 & 1.13 & Medium & 2 \\
\hline I can talk to other colleagues about the emotions I experience. & 3.35 & 1.10 & Medium & 1 \\
\hline Management of Own Emotions & Mean & SD & Level & Order \\
\hline I respect the opinion of my colleagues, even if I think they are wrong. & 3.28 & 1.14 & Medium & 1 \\
\hline When I am frustrated with my colleagues, I can overcome my frustration. & 3.17 & 1.12 & Medium & 2 \\
\hline $\begin{array}{l}\text { When deciding on a dispute, I try to see all sides of a disagreement before I come to } \\
\text { a conclusion. }\end{array}$ & 2.70 & 1.03 & Medium & 4 \\
\hline I give a fair hearing to my colleagues’ ideas. & 3.01 & 1.07 & Medium & 3 \\
\hline Awareness of Others' Emotions & Mean & SD & Level & Order \\
\hline I can read my colleagues "true" feelings, even if they try to hide them. & 3.00 & 1.08 & Medium & 4 \\
\hline I am able to describe accurately the way my colleagues are feeling. & 3.55 & 1.00 & High & 2 \\
\hline $\begin{array}{l}\text { When I talk to my colleagues I can gauge their true feelings from their body } \\
\text { language. }\end{array}$ & 3.50 & 1.03 & High & 3 \\
\hline I can tell when my colleagues don't mean what they say. & 3.56 & 1.09 & High & 1 \\
\hline Management of Others' Emotions & Mean & SD & Level & Order \\
\hline My enthusiasm can be contagious for my colleagues. & 3.01 & 1.11 & Medium & 4 \\
\hline I am able to cheer my colleagues up when they are feeling down. & 3.16 & 0.99 & Medium & 2 \\
\hline I can get my colleagues to share my keenness for a project. & 3.17 & 1.01 & Medium & 1 \\
\hline I can provide the "spark" to get my colleagues enthusiastic. & 3.13 & 1.13 & Medium & 3 \\
\hline Organizational Effectiveness & Mean & SD & Level & Order \\
\hline $\begin{array}{l}\text { Over the past two years, the department has improved its ability to innovate new } \\
\text { services. }\end{array}$ & 2.96 & 1.21 & Medium & 8 \\
\hline $\begin{array}{l}\text { Over the past two years, the department has improved its ability to identify new } \\
\text { business opportunities. }\end{array}$ & 3.34 & 1.05 & Medium & 2 \\
\hline $\begin{array}{l}\text { Over the past two years, the department has improved its ability to anticipate } \\
\text { potential market opportunities for new services. }\end{array}$ & 2.97 & 0.96 & Medium & 7 \\
\hline $\begin{array}{l}\text { Over the past two years, the department has improved its ability to rapidly } \\
\text { commercialize new innovations. }\end{array}$ & 3.03 & 1.10 & Medium & 6 \\
\hline $\begin{array}{l}\text { Over the past two years, the department has improved its ability to adapt to } \\
\text { unanticipated changes. }\end{array}$ & 3.19 & 1.12 & Medium & 4 \\
\hline $\begin{array}{l}\text { Over the past two years, the department has improved its ability to expect new } \\
\text { market surprises and crises. }\end{array}$ & 3.20 & 1.02 & Medium & 3 \\
\hline $\begin{array}{l}\text { Over the past two years, the department has improved its ability to quickly adapt its } \\
\text { goals and objectives to industry/market changes. }\end{array}$ & 2.86 & 1.17 & Medium & 12 \\
\hline $\begin{array}{l}\text { Over the past two years, the department has improved its ability to decrease market } \\
\text { response times. }\end{array}$ & 3.16 & 1.19 & Medium & 5 \\
\hline $\begin{array}{l}\text { Over the past two years, the department has improved its ability to react to new } \\
\text { information about the industry or market. }\end{array}$ & 2.78 & 1.13 & Medium & 13 \\
\hline $\begin{array}{l}\text { Over the past two years, the department has improved its ability to be responsive to } \\
\text { new market demands. }\end{array}$ & 2.92 & 1.06 & Medium & 10 \\
\hline $\begin{array}{l}\text { Over the past two years, the department has improved its ability to avoid overlapping } \\
\text { development of corporate initiatives. }\end{array}$ & 2.94 & 1.03 & Medium & 9 \\
\hline $\begin{array}{l}\text { Over the past two years, the department has improved its ability to streamline its } \\
\text { internal processes. }\end{array}$ & 2.90 & 1.18 & Medium & 11 \\
\hline $\begin{array}{l}\text { Over the past two years, the department has improved its ability to reduce } \\
\text { redundancy of information and knowledge. }\end{array}$ & 3.38 & 1.06 & Medium & 1 \\
\hline
\end{tabular}


checked. According to [46], all the values should be inside the adequate ranges for normality (i.e. -1.0 to +1.0 ). For this purpose, skewness and Variance Inflation Factor (VIF) were investigated; Table 5 includes the results.

As can be figured out from Table 5, the skewness values were within the normal values $(-1.0$ to +1.0$)$ suggesting that the data of the independent variables is normal. The VIF values were less than the critical value (10) which is most common among the most studies, suggesting no multi co-linearity problem among the independent variables. However, the results of testing the four hypotheses on the impact of emotional intelligence on organizational effectiveness are demonstrated in Table 6.

Refer to Table 6, the multiple correlation coefficient $\mathrm{R}=0.803$ indicates that there is a strong positive correlation between emotional intelligence (awareness of one's own emotion, management of one's own emotion, awareness of other's emotion, and management of other's emotion) and organizational effectiveness. The adjusted $\mathrm{R}^{2}$ indicated the generalizability of the model. It allows us to generalize the results taken from the respondents to the whole population. In this case it equals 0.644 . The results showed that F-ratio for these data is equal to 67.458 , which is statistically significant at $p<0.05$. Therefore, we conclude that there is a statistically significant effect of emotional intelligence on organizational effectiveness.

The $\beta$ indicates the individual contribution of each predictor (independent variable) to the model, if other predictors are held constant. Table 6 shows the standardized coefficients for each emotional intelligence dimensions. The value of $\beta$ for management of one's own emotion, awareness of other's emotion, and management of other's emotion are $0.201,0.178$, and 0.470 respectively, which are positive. While for awareness of one's own emotion, the value of $\beta$ is 0.059 , which a small value compared with other predictors. The level of effect of these variables depends on the $\beta$ value, the higher $\beta$ value the higher effect on dependent variable. We can infer from the values of beta that the variable that has the highest contribution in the model is management of others' emotions, followed by management of own emotions, and then awareness of others' emotions. The variable awareness of own emotions does not have a significant effect on organizational effectiveness.

Hypotheses H5A, H5B, and H5C argued that there is a significant difference in the impact of emotional intelligence on organizational effectiveness due to gender, age, and experience. Independent Samples T-test was employed in order to investigate if there any significant differences in the impact of emotional intelligence on organizational effectiveness that can be attributed to gender. Also, ANOVA test was employed to examine if there any significant differences in the impact of emotional intelligence on organizational effectiveness that can be attributed to age and experience. Results of T-test, shown in Table 7, indicated that there is no significant difference in the impact of emotional intelligence on organizational effectiveness that can be attributed to gender. However, results of ANOVA test, shown in Table 8, and Table 9, indicated that there is a significant difference in the impact of emotional intelligence on organizational effectiveness in favor of age and experience. Therefore, Table 10 and Table 11 provided the statistical significance of the differences between each pair of groups for

Table 5. Skewness and VIF for the independent variables.

\begin{tabular}{|c|c|c|c|}
\hline Variables & Tolerance & VIF & Skewness \\
\hline Awareness of Own Emotions & 0.464 & 2.157 & 0.613 \\
\hline Management of Own Emotions & 0.428 & 2.336 & 0.521 \\
\hline Awareness of Others' Emotions & 0.424 & 2.360 & 0.865 \\
\hline Management of Others' Emotions & 0.452 & 2.212 & 0.659 \\
\hline
\end{tabular}

Table 6. Result for the study model .

\begin{tabular}{|c|c|c|c|c|c|c|c|}
\hline Variable & $\mathbf{r}$ & $\mathbf{R}^{2}$ & f & Sig (f) & $\boldsymbol{\beta}$ & $\mathbf{t}$ & Sig $(t)$ \\
\hline Awareness of Own Emotions & \multirow{4}{*}{0.803} & \multirow{4}{*}{0.644} & \multirow{4}{*}{67.458} & \multirow{4}{*}{$0.000^{\mathrm{a}}$} & 0.059 & 0.829 & 0.409 \\
\hline Management of Own Emotions & & & & & 0.201 & 2.686 & 0.008 \\
\hline Awareness of Others’ Emotions & & & & & 0.178 & 2.372 & 0.019 \\
\hline Management of Others' Emotions & & & & & 0.470 & 6.467 & 0.000 \\
\hline
\end{tabular}

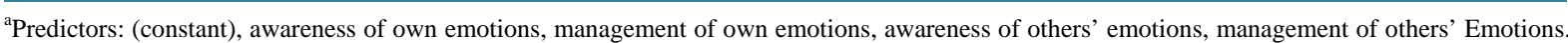
${ }^{\mathrm{b}}$ Dependent variable: organizational effectiveness. 
Table 7. T-test of the use of emotional intelligence on organizational effectiveness attributed to gender.

\begin{tabular}{|c|c|c|c|c|c|c|c|c|c|}
\hline \multirow{2}{*}{ Variables } & \multicolumn{3}{|c|}{ Male } & \multicolumn{3}{|c|}{ Female } & \multirow{2}{*}{$\mathbf{T}$} & \multirow{2}{*}{ df } & \multirow{2}{*}{ Sig. } \\
\hline & $\mathbf{N}$ & Mean & Std. Dev. & $\mathbf{N}$ & Mean & Std. Dev. & & & \\
\hline $\begin{array}{l}\text { Organizational } \\
\text { Effectiveness }\end{array}$ & 118 & 3.0130 & 0.72519 & 36 & 3.1902 & 0.79079 & 1.256 & 152 & 0.211 \\
\hline
\end{tabular}

Table 8. ANOVA Analysis of emotional intelligence on organizational effectiveness attributed to age.

\begin{tabular}{ccccccc}
\hline Variables & & Sum of Squares & Df & Mean Square & F & Sig. \\
\hline & Between Groups & 15.726 & 3 & 5.242 & 11.469 & 0.000 \\
Organizational & Within Groups & 68.557 & 150 & 0.457 & & \\
Effectiveness & Total & 84.283 & 153 & & & \\
& & & & & & \\
\hline
\end{tabular}

Table 9. ANOVA Analysis of emotional intelligence on organizational effectiveness attributed to experience.

\begin{tabular}{cccccc}
\hline Variables & & Sum of Squares & Df & Mean Square & F \\
\hline & Between Groups & 12.371 & 3 & 4.124 & 0.000 \\
Organizational & Within Groups & 71.912 & 150 & 0.479 \\
Effectiveness & Total & 84.283 & 153 & \\
\hline
\end{tabular}

age and experience respectively.

As noticed in Table 10, the three groups (i.e. 24 years-less than 30, 40-less than 50, 50 and above) were statistically different from one another, whereas 30-less than 40 did not.

Table 11 shows that the three groups (i.e. Less than 5 years, 5-less than 10 years, 15 years and more) were statistically different from one another, while 10 -less than 15 years did not.

\section{Conclusions}

The aim of this research was to explore the impact of emotional intelligence (awareness of one's own emotion, management of one's own emotion, awareness of other's emotion, and management of other's emotion) on organizational effectiveness in Jordanian public shareholding firms. The research tested five hypotheses as the passages below going to discuss each of them. The current study found that there were significant positive impacts of management of one's own emotion, awareness of other's emotion, and management of other's emotion on organizational effectiveness, whereas awareness of one's own emotion did not have a significant impact on organizational effectiveness. In addition, the results revealed that there was no significant difference in the impact of emotional intelligence on organizational effectiveness that could be attributed to gender. However, results of ANOVA test indicated that there were significant differences in the impact of emotional intelligence on organizational effectiveness in favor of age and experience. This section discussed the findings of the study presented in the previous section, presented implications and recommendations for further empirical research and drew the limitations as well.

H1: There is a statistically significant impact of awareness of one's own emotion on organizational effectiveness.

Previous studies have indicated that awareness of one's own emotion positively affects organizational effectiveness ([1] [22] [47]). The results of this study however are inconsistent with the conclusions reached by these studies, in which those Jordanian IT managers' awareness of one's own emotion who work in public shareholding firms do not impact their organizational effectiveness. Indeed, awareness of one's own emotion is not a predictor of organizational effectiveness $(\beta=0.059$, $\mathrm{t}$-value $=0.829$, sig. $=0.409$ ). This may be due to the fact that managers in the Arab cultures do not express their emotions fair enough as indicated by [48]. In other words, it seems that Jordanian IT managers cannot talk to their colleagues about the emotions they experience; if they feel down, they cannot tell their colleagues what will make them feel better; cannot discuss the emotions they feel with their colleagues, and cannot explain the emotions they feel to their colleagues. 
Table 10. Multiple comparisons analysis of emotional intelligence on organizational effectiveness attributed to age.

\begin{tabular}{|c|c|c|c|c|c|c|}
\hline \multirow[b]{2}{*}{$\begin{array}{l}\text { (I) } \\
\text { Age }\end{array}$} & \multirow[b]{2}{*}{$\begin{array}{l}\text { (J) } \\
\text { Age }\end{array}$} & \multirow[b]{2}{*}{$\begin{array}{c}\text { Mean } \\
\text { Difference (I-J) }\end{array}$} & \multirow[b]{2}{*}{ Std. Error } & \multirow[b]{2}{*}{ Sig. } & \multicolumn{2}{|c|}{ 95\% Confidence Interval } \\
\hline & & & & & $\begin{array}{l}\text { Lower } \\
\text { Bound }\end{array}$ & $\begin{array}{l}\text { Upper } \\
\text { Bound }\end{array}$ \\
\hline $\begin{array}{l}24 \text { years-less } \\
\text { than } 30\end{array}$ & $\begin{array}{l}\text { 30-less than } 40 \\
40 \text {-less than } 50 \\
50 \text { and above }\end{array}$ & $\begin{array}{l}0.12140 \\
0.52650^{*} \\
0.84423^{*}\end{array}$ & $\begin{array}{l}0.202101 \\
0.20156 \\
0.19998\end{array}$ & $\begin{array}{l}0.931 \\
0.048 \\
0.000\end{array}$ & $\begin{array}{c}-0.4008- \\
0.0028 \\
0.3247\end{array}$ & $\begin{array}{l}0.6436 \\
1.0502 \\
1.3638\end{array}$ \\
\hline 30-less than 40 & $\begin{array}{c}24 \text { years-less than } 30 \\
40 \text {-less than } 50 \\
50 \text { and above }\end{array}$ & $\begin{array}{l}-0.12140 \\
0.40509^{*} \\
0.72283^{*}\end{array}$ & $\begin{array}{l}0.20101 \\
0.14175 \\
0.13949\end{array}$ & $\begin{array}{l}0.931 \\
0.025 \\
0.000\end{array}$ & $\begin{array}{c}-0.6436- \\
0.0368 \\
0.3604\end{array}$ & $\begin{array}{l}0.4008 \\
0.7734 \\
1.0852\end{array}$ \\
\hline 40-less than 50 & $\begin{array}{c}24 \text { years-less than } 30 \\
30 \text {-less than } 40 \\
50 \text { and above }\end{array}$ & $\begin{array}{c}-0.52650^{-}{ }^{*} \\
-0.40509-^{*} \\
0.31774\end{array}$ & $\begin{array}{l}0.20156 \\
0.14175 \\
0.14028\end{array}$ & $\begin{array}{l}0.048 \\
0.025 \\
0.111\end{array}$ & $\begin{array}{l}-1.0502- \\
-0.7734- \\
-0.0467-\end{array}$ & $\begin{array}{c}-0.0028- \\
-0.0368- \\
0.6822\end{array}$ \\
\hline 50 and above & $\begin{array}{c}24 \text { years-less than } 30 \\
\text { 30-less than } 40 \\
\text { 40-less than } 50\end{array}$ & $\begin{array}{l}-0.84423-^{*} \\
-0.72283^{-*} \\
-0.31774-\end{array}$ & $\begin{array}{l}0.19998 \\
0.13949 \\
0.14028\end{array}$ & $\begin{array}{l}0.000 \\
0.000 \\
0.111\end{array}$ & $\begin{array}{l}-1.3638- \\
-1.0852- \\
-0.6822-\end{array}$ & $\begin{array}{c}-0.3247- \\
-0.3604- \\
0.0467\end{array}$ \\
\hline
\end{tabular}

*The mean difference is significant at the 0.05 level.

Table 11. Multiple comparisons analysis of emotional intelligence on organizational effectiveness attributed to experience.

\begin{tabular}{|c|c|c|c|c|c|c|}
\hline \multirow[b]{2}{*}{$\begin{array}{c}\text { (I) } \\
\text { Age }\end{array}$} & \multirow[b]{2}{*}{$\begin{array}{c}\text { (J) } \\
\text { Age }\end{array}$} & \multirow{2}{*}{$\begin{array}{c}\text { Mean } \\
\text { Difference } \\
(\mathbf{I}-\mathbf{J})\end{array}$} & \multirow[b]{2}{*}{ Std. Error } & \multirow[b]{2}{*}{ Sig. } & \multicolumn{2}{|c|}{ 95\% Confidence Interval } \\
\hline & & & & & $\begin{array}{l}\text { Lower } \\
\text { Bound }\end{array}$ & $\begin{array}{l}\text { Upper } \\
\text { Bound }\end{array}$ \\
\hline $\begin{array}{c}\text { Less than } 5 \\
\text { years }\end{array}$ & $\begin{array}{c}5 \text {-less than } 10 \text { years } \\
\text { 10-less than } 15 \text { years } \\
15 \text { years and more }\end{array}$ & $\begin{array}{c}0.00501 \\
0.22889 \\
0.64745^{*}\end{array}$ & $\begin{array}{l}0.14952 \\
0.18917 \\
0.15366\end{array}$ & $\begin{array}{l}1.000 \\
0.622 \\
0.000\end{array}$ & $\begin{array}{c}-0.3835^{-} \\
-0.2626- \\
0.2482\end{array}$ & $\begin{array}{l}0.3935 \\
0.7204 \\
1.0467\end{array}$ \\
\hline $\begin{array}{c}\text { 5- less than } 10 \\
\text { years }\end{array}$ & $\begin{array}{c}\text { Less than } 5 \text { years } \\
\text { 10-less than } 15 \text { years } \\
15 \text { years and more }\end{array}$ & $\begin{array}{c}-0.00501- \\
0.22387 \\
0.64243^{*}\end{array}$ & $\begin{array}{l}0.14952 \\
0.17953 \\
0.14161\end{array}$ & $\begin{array}{l}1.000 \\
0.598 \\
0.000\end{array}$ & $\begin{array}{c}-0.3935- \\
-0.2425- \\
0.2745\end{array}$ & $\begin{array}{l}0.3835 \\
0.6903 \\
1.0104\end{array}$ \\
\hline $\begin{array}{c}\text { 10- less than } 15 \\
\text { years }\end{array}$ & $\begin{array}{l}\text { Less than } 5 \text { years } \\
\text { 5-less than } 10 \text { years } \\
15 \text { years and more }\end{array}$ & $\begin{array}{c}-0.22889- \\
-0.22387- \\
0.41856\end{array}$ & $\begin{array}{l}0.18917 \\
0.17953 \\
0.18298\end{array}$ & $\begin{array}{l}0.622 \\
0.598 \\
0.106\end{array}$ & $\begin{array}{l}-0.7204- \\
-0.6903- \\
-0.0568-\end{array}$ & $\begin{array}{l}0.2626 \\
0.2425 \\
0.8940\end{array}$ \\
\hline $\begin{array}{l}15 \text { years and } \\
\text { more }\end{array}$ & $\begin{array}{l}\text { Less than } 5 \text { years } \\
\text { 5-less than } 10 \text { years } \\
\text { 10-less than } 15 \text { years }\end{array}$ & $\begin{array}{l}-0.64745^{-*} \\
-0.64243^{*} \\
-0.41856^{-}\end{array}$ & $\begin{array}{l}0.15366 \\
0.14161 \\
0.18298\end{array}$ & $\begin{array}{l}0.000 \\
0.000 \\
0.106\end{array}$ & $\begin{array}{l}-1.0467- \\
-1.0104- \\
-0.8940-\end{array}$ & $\begin{array}{c}-0.2482- \\
-0.2745- \\
0.0568\end{array}$ \\
\hline
\end{tabular}

*The mean difference is significant at the 0.05 level.

H2: There is a statistically significant impact of management of one's own emotion on organizational effectiveness.

The results of testing the second main hypothesis reveal that management of one's own emotion and organizational effectiveness are significantly related. Thus, it can be concluded that IT managers confirm a tendency for high levels of organizational effectiveness in public shareholding firms in Jordan. This finding confirms the findings obtained in other studies that managing managers own emotion is found to be related to organizational effectiveness in the workplace [47] [49]. The premise behind this finding may relate to the fact that managers with high levels of self-management of emotions (such as respecting the opinion of other employees even if they are wrong, overcoming the resulted frustrations, and hearing all disputed parties to solve problems) are able to improve the organizational processes, procedures, products and services.

H3: There is a statistically significant impact of awareness of other's emotion on organizational effectiveness.

The results of testing the third main hypothesis indicated a positive significant effect of awareness of other's emotion on organizational effectiveness. This result is consistent with the results obtained by researchers such as [50] that the high level of awareness of colleagues' emotion, the more positive impact on their performance. Indeed, understanding when colleagues don't mean what they say, telling accurately the way they are feeling, their body language, and reading their true feelings; assist managers in their decision makings, and make them excellent problem solvers, besides boosting their ability to quickly adapt to the organizational goals and objectives.

H4: There is a statistically significant impact of management of other's emotion on organizational effectiveness. 
The results of this study showed that management of other's emotion was the strongest predictor of organizational effectiveness $(\beta=0.470$, t-value $=6.467$, sig. $=0.000)$. The study revealed that management of other's emotion significantly predicted organizational effectiveness, which is consistent with the findings of other studies such as [40] and [51]. Indeed, the ability to positively influence others' emotions in various ways such as through the managers' ability to get their colleagues share the enthusiasm toward specific projects, and cheering up the colleagues when facing obstacles; will improve the organizational effectiveness.

Unlike [41] findings of the key role of gender impact on emotional intelligence, the current research found that there is no significant difference in the impact of emotional intelligence on organizational effectiveness due to gender; whereas significant differences were found due to age and experience. This is to say that gender did not play an important role for emotional intelligence competencies on organizational effectiveness, while both age and experience did. Indeed, as shown in Table 10, the groups of (24 years-less than 30, 40-less than 50, 50 and above) were statistically different from one another, whereas 30-less than 40 did not; and as illustrated in Table 11 that the groups of (Less than 5 years, 5-less than 10 years, 15 years and more) were statistically different from one another, while 10-less than 15 years did not. Consequently, both age and experience do play a crucial role in the impact of emotional intelligence on organizational effectiveness.

To sum, the motivation of this study was to determine the impact of emotional intelligence (awareness of one's own emotion, management of one's own emotion, awareness of other's emotion, and management of other's emotion) on organizational effectiveness in Jordanian public shareholding firms. A theoretical model was proposed and empirical testing was completed using a sample of 154 IT managers at Jordanian public shareholding firms. The findings increase our understanding of the emotional intelligence, and their associations with the context of organizational effectiveness. However, there are some limitations of the study. The first limitation is the use of the same informant for the independent and dependent variables. Even though the researcher tried to reduce data incorrectness by asking the best positioned to answer the questionnaire (IT managers), consequently, further research should consider both technical and non-technical staff not only to avoid depending on a single source of information as a way of testing the research model from several perceptions, but also as an attempt to evidence the source of any differences between them. Another limitation is that the proposed conceptual model is based on the cross-sectional data from IT managers in Jordanian public shareholding firms. Consequently, longitudinal investigations are preferred for better implications of the emotional intelligence practices. Also, it might be possible that examining the main constructs in this study over a longer period yield more insights into the associations between the research variables on organizational effectiveness.

Furthermore, even though the response rate of this study was sufficient for the condition of statistical analysis, the percentage of those who did not respond was still observable. In other words, even though the research results could be representative, it is reasonable to be watchful in its generalization. Thus, to increase statistical validity, then further research should consider higher response rates. As well, the data and results reported in this study were based on a single country, Jordan, and in turn are applicable specifically to the Jordanian context. Thus, this raises inquiries regarding the generalizability to other cultures and different contexts. Hence, further research is needed with regards to several countries since this would help to advance understanding of the emotional intelligence practices and the conditions and outcomes of achieving it from different nationwide origins in different contexts. Indeed, although this study investigated several hypotheses and offered empirical support for the acceptance and refusal of some of these hypotheses; more generalizations on the application of the theoretical premises that developed in building the research model will be needed. This is to say, a more generalized research model that compensate the current research limitations by adding further impacting variables to the model and obtain a more representative sample from different sectors is needed.

\section{References}

[1] Vratskikh, I., Masa'deh, R., Al-Lozi, M. and Maqableh, M. (2016) The Impact of Emotional Intelligence on Job Performance via the Mediating Role of Job Satisfaction. International Journal of Business and Management, 11, 69-91. http://dx.doi.org/10.5539/ijbm.v11n2p69

[2] Al-Shurman, B.A. (2009) The Influence of Emotional Intelligence Training on Nurses’ Job Satisfaction; a Quasi Experimental Study. Unpublished Master’s Thesis, Jordan University of Science and Technology, Irbid.

[3] Alawneh, A.R. (2013) Relationship between the Emotional Intelligence Level and the Effectiveness of a Project Manager. Unpublished Master's Thesis, University of Jordan, Amman.

[4] Zeidner, M., Matthews, G. and Roberts, R.D. (2012) Emotional Intelligence: A Promise Unfulfilled? Japanese Psy- 
chological Research, 54, 105-127. http://dx.doi.org/10.1111/j.1468-5884.2011.00502.x

[5] Beck, J.H. (2013) Emotional Intelligence in Everyday Life. Psychology Press.

[6] Pachulia, G. and Henderson, L. (2009) The Relationship between Emotional Intelligence and Entrepreneurial Orientation Observed within Owner-Managers Who Lead Small, High-Tech Firms in Sweden. Jonkoping University, Sweden.

[7] Zeidner, M., Matthews, G. and Roberts, R. (2002) What We Know about Emotional Intelligence: How It Affects Learning, Work, Relationships, and Our Mental Health. MIT Press, Location.

[8] Goleman, D. (1995) Emotional Intelligence. Bantam Books, New York.

[9] Petrides, K.V. and Furnham, A. (2000) On the Dimensional Structure of Emotional Intelligence. Personality and Individual Differences, 29, 313-320. http://dx.doi.org/10.1016/S0191-8869(99)00195-6

[10] Mayer, J.D. and Salovey, P. (1990) Emotional Intelligence, Imagination, Cognition, and Personality. Cognition and Personality, 9, 185-211.

[11] Stys, Y. and Brown, S.L. (2004) A Review of the Emotional Intelligence Literature and Implications for Corrections. Correctional Service Canada. http://www.cscscc.gc.ca/text/rsrch/reports/r150/r150_e.pdf

[12] Perez, J., Petrides, K. and Furnham, A. (2004) Measuring Trait Emotional Intelligence, International Handbook of Emotional Intelligence. Hogrefe \& Huber, Cambridge, 124-139.

[13] Bar-On, R. and Parker, J. (2000) The Handbook of Emotional Intelligence: Theory, Development, Assessment, and Application at Home, School, and in the Workplace. Jossey-Bass, San Francisco.

[14] Petrides, K.V. and Furnham, A. (2001) Trait Emotional Intelligence: Psychometric Investigation with Reference to Established Trait Taxonomies. European Journal of Personality, 15, 425-448. http://dx.doi.org/10.1002/per.416

[15] Petrides, K.V. (2011) Ability and Trait Emotional Intelligence. The Wiley-Blackwell Handbook of Individual Differences, 658. http://dx.doi.org/10.1002/9781444343120.ch25

[16] Mayer, J.D., Salovey, P. and Caruso, D.R. (2000) Models of Emotional Intelligence. In: Sternberg, R.J., Ed., Handbook of Intelligence, Cambridge University Press, Cambridge, 396-420. http://dx.doi.org/10.1017/cbo9780511807947.019.

[17] Mayer, J.D. and Salovey, P. (1997) What Is Emotional Intelligence? Emotional Development and Emotional Intelligence: Implications for Educators. Basic Books, New York, 3-31.

[18] Fernández-Berrocal, P. and Extremera, N. (2006) Emotional Intelligence: A Theoretical and Empirical Review of Its First 15 Years of History. Psicothema, 18, 7-12.

[19] Davar, S.C. and Singh, N. (2014) Emotional Intelligence and Job Performance in Banking and Insurance Sector in India. Indian Journal of Industrial Relations, 49, 722-733.

[20] Ratnaprabha, S. and Shanbhag, D. (2013) Emotional Intelligence and Scholastic Performance among Children of a High School in South of India. International Journal of Collaborative Research on Internal Medicine and Public Health, 5, 359-367.

[21] Shooshtarian, Z., Ameli, F. and Aminilari, M. (2013) The Effect of Labor's Emotional Intelligence on Their Job Satisfaction, Job Performance, and Job Commitment. Iranian Journal of Management Studies, 6, 27-43.

[22] Konkin, J. (2013) The Moderating Effect of Emotional Labor on the Relationships of Emotional Intelligence and Adjustment with Managerial Job Performance. Allinat International University, San Diego, 299.

[23] Coetzer, W.C. (2013) The Relationship between Emotional Intelligence and Job Satisfaction amongst Westcol FET Lecturers.

[24] Hülya, G.Ç., Günsel, A. and TuğçeUlutaş, T. (2012) Effects of Emotional Intelligence on Job Satisfaction: An Empirical Study on Call Center Employees. Procepedia—Social Behaviour Sciences, 58, 363-369. http://dx.doi.org/10.1016/j.sbspro.2012.09.1012

[25] Mishra, P.S. and Mohapatra, A.K. (2010) Relevance of Emotional Intelligence for Effective Job Performance: An Empirical Study. Vikalpa, 35, 53-61.

[26] Lopes, P.N., Grewal, D., Kadis, J., Gall, M. and Salovey, P. (2006) Evidence that Emotional Intelligence Is Related to Job Performance and Affect and Attitudes at Work. Psicothema, 18, 132-138.

[27] Rau, W.A. (2001) The Relationship of Emotional Intelligence Test Scores to Job Performance Evaluation Scores in the Management Group of a Health Care Organization. Medical University of South Carolina, Charleston.

[28] Moon, T.W. and Hur, W. (2011) Emotional Intelligence, Emotional Exhaustion and Job Performance. Social Behavior and Personality, 39, 1087-1096. http://dx.doi.org/10.2224/sbp.2011.39.8.1087

[29] Arghode, V. (2013) Emotional and Social Intelligence Competence: Implications for Instruction. International Journal of Pedagogies and Learning, 8, 66-77. http://dx.doi.org/10.5172/ijpl.2013.8.2.66

[30] Sarwar, S. and Abugre, J. (2013) The Influence of Rewards and Job Satisfaction on Employees in the Service Industry 
Swansea University, Wales, UK. The Business \& Management Review, 3, 22-32.

[31] Turnipseed, D. and Vandewaa, E. (2012) Relationship between Emotional Intelligence and Organizational Citizenship Behavior. Psychological Reports, 110, 899-914.

[32] Singh, Y. and Sharma, R. (2012) Relationship between General Intelligence, Emotional Intelligence, Stress Levels and Stress Reactivity. Annals of Neurosciences, 19, 107-111. http://dx.doi.org/10.5214/ans.0972.7531.190304

[33] Jha, A. and Singh, I. (2012) Teacher Effectiveness in Relation to Emotional Intelligence among Medical and Engineering Faculty Members. Europe’s Journal of Psychology, 8, 667-685.

[34] Esfahania, N. and Soflub, H.G. (2011) Relationship between Emotional Intelligence and Transformational Leadership in Physical Education Managers. Procepedia-Social Behaviour Sciences, 30, 2384-2393.

http://dx.doi.org/10.1016/j.sbspro.2011.10.465

[35] Srivastava, N. and Nair, S.K. (2010) Emotional Intelligence and Managerial Effectiveness: The Moderating Role of Rational Emotive Behaviour. The Indian Journal of Industrial Relations, 46, 313-327.

[36] Othman, A., Abdullah, H. and Ahmad, J. (2009) Emotional Intelligence, Emotional Labor and Work Effectiveness in Service Organizations: A Proposed Model. The Journal of Business Perspective, 12, 31-42. http://dx.doi.org/10.1177/097226290801200105

[37] Groves, K.S., McEnrue, M.P. and Shen, W. (2008) Developing and Measuring the Emotional Intelligence of Leaders. Journal of Management Development, 27, 225-250. http://dx.doi.org/10.1108/02621710810849353

[38] Koman, E.S. and Wolff, S.B. (2007) Emotional Intelligence Competencies in the Team and Team Leader. Journal of Management Development, 27, 55-75.

[39] Harter, J., Schmidt, F. and Hayes, T. (2002) Business-Unit-Level Relationship between Employee Satisfaction, Employee Engagement, and Business Outcomes: A Meta-Analysis. Journal of Applied Psychology, 87, 268-279. http://dx.doi.org/10.1037/0021-9010.87.2.268

[40] Jordan, P.J. and Lawrence, S.A. (2009) Emotional Intelligence in Teams: Development and Initial Validation of the Short Version of the Workgroup Emotional Intelligence Profile (WEIP-S). Journal of Management and Organization, 15, 452-469. http://dx.doi.org/10.5172/jmo.15.4.452

[41] Dunaway, M. (2013) IS Learning: The Impact of Gender and Team Emotional Intelligence. Journal of Information Systems Education, 24, 189-202.

[42] Gold, A., Malhotra, A. and Segars, A. (2001) Knowledge Management: An Organizational Capabilities Perspective. Journal of Management Information Systems, 18, 185-214.

[43] Sekaran, U. and Bougie, R. (2013) Research Methods for Business: A Skill-Building Approach. 6th Edition, Wiley, New York.

[44] Bagozzi, R. and Yi, Y. (1988) On the Evaluation of Structural Evaluation Models. Journal of the Academy of Marketing Science, 16, 74-94. http://dx.doi.org/10.1007/BF02723327

[45] Creswell, J. (2009) Research Design: Qualitative, Quantitative, and Mixed Methods Approaches. 3rd Edition, Sage Publications, Thousand Oaks.

[46] Pallant, J. (2005) SPSS Survival Manual: A Step Guide to Data Analysis Using SPSS for Windows Version 12. Open University Press, Chicago.

[47] Quoidbach, J. and Hansenne, M. (2009) The Impact of Trait Emotional Intelligence on Nursing Team Performance and Cohesiveness. Journal of Professional Nursing, 25, 23-29. http://dx.doi.org/10.1016/j.profnurs.2007.12.002

[48] Obeidat, B., Shannak, R., Masa'deh, R. and Al-Jarrah, I. (2012) Toward Better Understanding for Arabian Culture: Implications Based on Hofstede’s Cultural Model. European Journal of Social Sciences, 28, 512-522.

[49] Daus, C.S. and Ashkanasy, N.M. (2005) The Case for the Ability-Based Model of Emotional Intelligence in Organizational Behavior. Journal of Organizational Behavior, 26, 453-466. http://dx.doi.org/10.1002/job.321

[50] Laszlo, A., Laszlo, K.C. and Johnsen, C.S. (2009) From High-Performance Teams to Evolutionary Learning Communities: New Pathways in Organizational Development. Journal of Organisational Transformation \& Social Change, 6, 29-48. http://dx.doi.org/10.1386/jots.6.1.29 1

[51] Turner, R. and Lloyd-Walker, B. (2008) Emotional Intelligence (EI) Capabilities Training: Can It Develop EI in Project Teams? International Journal of Managing Projects in Business, 1, 512-534. http://dx.doi.org/10.1108/17538370810906237 